\title{
DC Voltage Adaptive Droop Control Strategy for Hybrid Multi-Terminal HVDC Sys- tem
}

\author{
Yingpei Liu ${ }^{1}$, La Zhang ${ }^{1}$, Haiping Liang ${ }^{1}$, Zhengping Wang ${ }^{2}$, Wei Zhao ${ }^{2}$, Zhikun Xing ${ }^{2}$ \\ 1. School of Electrical and Electronic Engineering, North China Electric Power University \\ Baoding 071003, Hebei Province, China \\ 2. Cangzhou Power Supply Company of State Grid Corporation of China \\ Cangzhou 061001, Hebei Province, China \\ E-mail: liuyingpei_123@126.com
}

\begin{abstract}
In order to solve the problems of coordination control in the hybrid multi-terminal high voltage direct current (hybridMTDC) system effectively, a DC voltage adaptive droop control strategy based on DC voltage-current characteristics is proposed. By introducing the droop coefficient influence factor, the proposed control strategy can adjust the droop coefficient according to the dynamic power margin of the converter station, so that the converter station can participate in power regulation according to its own power regulating ability. Consequently, the strategy allocates the power reasonably and minimizes the DC voltage deviation. Simulation results have verified the feasibility and effectiveness of the proposed control strategy.
\end{abstract}

Key words: hybrid multi-terminal high voltage direct current system, adaptive droop control, droop coefficient influence factor, DC voltage deviation

\section{Introduction}

Line commutated converter based high voltage direct current (LCC-HVDC) system has been widely utilized in many areas due to high power capability, low losses and economic advantages. However, LCC-HVDC has a strong dependence on AC grid [1]. Nowadays, voltage source converter based high voltage direct current (VSC-HVDC) has been developing rapidly. It has many advantages such as independent control of active power and reactive power, ability to provide dynamic reactive power support for AC grid. Due to its advantages, it is a potential solution to the new energy gridconnection. However, VSC-HVDC are worse than LCCHVDC in cost and losses [2].

Hybrid high voltage direct current (hybrid-HVDC) system combining the advantages of LCC-HVDC and VSC-HVDC is formed with VSC and LCC. With the increasing demand of new energy grid-connection, the hybrid multi-terminal HVDC (hybrid-MTDC) system has become the inevitable development trend of the HVDC transmission system [3]-[4].

The control system of hybrid-MTDC system is more complex. Therefore, it is necessary to study the coordinated control strategy of hybrid-MTDC to improve the ability of power regulation [5]. In [6], a control method, based on frequencydomain stability analysis, is presented to provide a selection standard for the droop coefficient to maintain the power balance of the MTDC system. In [7]-[8], the optimal solutions of DC voltage and active power instructions for each converter station are obtained at the upper controllers to improve the droop control performance. Aiming at the situations of DC voltage oscillations caused by AC side faults, reference [9] improves traditional DC voltage droop control strategy by introducing a common DC voltage reference value, which improves the stability of the system. Reference [10] proposes a power sharing adaptive droop control method, which takes account of the dynamic power margin of the converter station to avoid overload. In [11], converter stations are divided into four converter station groups that are set different voltage margins and dead zones to set the priority level for coordinated control. As a result, converter stations have good dynamic characteristics in the transient state.

In this paper, a DC voltage adaptive droop control strategy based on DC voltage-current characteristics is studied. The proposed control strategy can adjust the droop coefficient in real time by the droop coefficient influence factor. Consequently, the control strategy allocates the power reasonably and minimizes the DC voltage deviation. Finally, the feasibility and effectiveness of the proposed control strategy have been verified through simulation analyses of a four-terminal hybrid HVDC system performed in PSCAD/EMTDC.

\section{Hybrid-MTDC System}

The topology of parallel four-terminal hybrid HVDC system is shown in Fig. 1. VSC1 and VSC2 are rectifier stations, while LCC3 and LCC4 are inverter stations. $T_{i}$ is the converter transformer of $i^{\text {th }}(i=1,2,3,4)$ converter station. $P_{i}$ and $Q_{i}$ are active power and reactive power of $i^{t h}$ converter station, respectively.

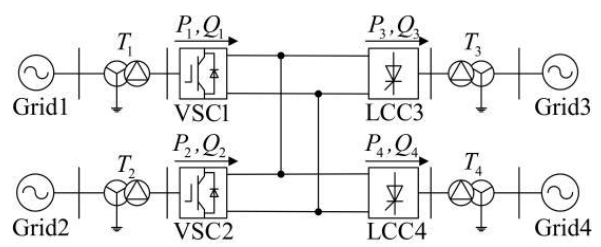

Fig. 1 The topology of parallel four-terminal hybrid HVDC system

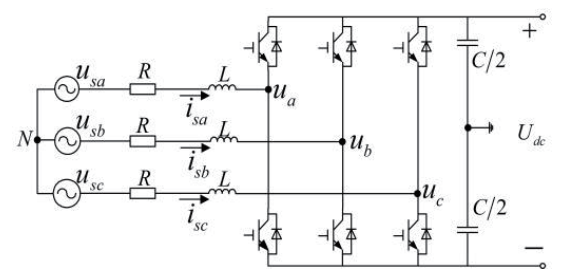

Fig. 2 Structure of VSC 
The mathematical model of VSC in $d q$ reference frame is

$$
\left\{\begin{array}{l}
L \frac{d i_{s d}}{d t}=-R i_{s d}+\omega L i_{s q}+u_{s d}-u_{d} \\
L \frac{d i_{s q}}{d t}=-R i_{s q}-\omega L i_{s d}+u_{s q}-u_{q}
\end{array}\right.
$$

where $u_{s d}$ and $u_{s q}$ are components of the AC grid voltage in the $d q$ aixs respectively; $u_{d}$ and $u_{q}$ are components of the fundamental component of converter's output voltage in the $d q$ aixs respectively; $i_{s d}$ and $i_{s q}$ are the components of the AC grid current in the $d q$ aixs respectively; $\omega$ is the synchronous rotating angular velocity of AC grid voltage vector.

The structure of LCC converter station, which mainly consists of 12 pulse converter, converter transformer, AC filter and smoothing reactor, is shown in Fig. 3.

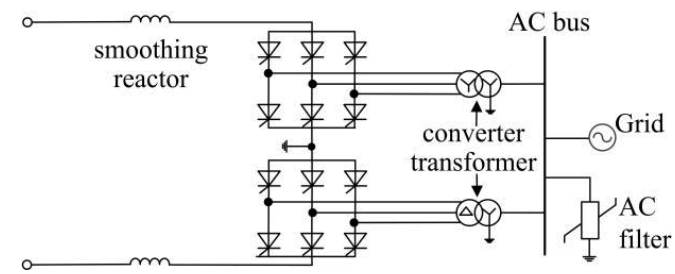

Fig. 3. Structure of line commutated converter station

As the inverter station, the mathematical model of LCC is

$$
U_{d c}=\frac{3 \sqrt{2}}{\pi} U_{2 L} \cos \beta+\frac{3}{\pi} X_{c} I_{d c}
$$

where $U_{d c}$ and $I_{d c}$ are the DC voltage and DC current of the converter station respectively; $U_{2 L}$ is the effective value of line voltage at the transformer secondary-side; $\beta$ is advance firing angle; $X_{c}$ is the equivalent commutation reactance.

\section{Voltage Adaptive Droop Control}

The traditional DC voltage droop control structure is shown in Fig. 4. In Fig.4, $U_{d c r e f}$ and $I_{d c r e f}$ are the DC voltage and DC current reference values of the converter station respectively, $K$ is the droop coefficient.

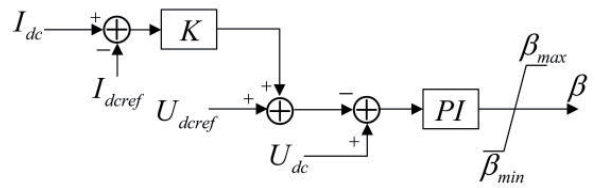

Fig. 4 traditional DC voltage droop controller

As can be observed from Fig. 4, the relationship between the DC voltage and DC current is

$$
U_{d c}-U_{d c r e f}=K\left(I_{d c}-I_{d c r e f}\right)
$$

When power flow changes in the hybrid-MTDC system occur, the stable operating point of the converter station changes, then the DC voltage deviation is

$$
\Delta U_{d c}=U_{d c}-U_{d c r e f}=K\left(I_{d c}-I_{d c r e f}\right)
$$

In addition, the unbalanced power shared by the converter station is

$$
\Delta P=U_{d c} I_{d c}-U_{d c r e f} I_{d c r e f}=U_{d c r e f}\left(I_{d c}-I_{d c r e f}\right)+\Delta U_{d c} I_{d c}
$$

In terms of the traditional DC voltage droop control strategy, the traditional droop coefficient $\mathrm{K}$ is described as follows

$$
K=\frac{U_{d c \max }-U_{d c r e f}}{I_{d c \max }}
$$

Where $U_{d c \max }$ and $I_{d c \max }$ are the upper limit of the DC voltage and DC current respectively; $U_{d c m a x}-U_{d c r e f}$ is the upper limit of the DC voltage deviation, which generally takes $5 \%$ of $U_{d c r e f}$.

According to (4) and (6), Equation (7) can be obtained as follow

$$
\frac{\Delta U_{d c} I_{d c}}{U_{d c r e f}\left(I_{d c}-I_{d c r e f}\right)} \leq 5 \%
$$

That is to say, $\Delta U_{d c} I_{d c}$ is so small that it can be ignored compared with $U_{d c r e f}\left(I_{d c}-I_{d c r e f}\right)$. Therefore, the unbalanced power shared by the converter station can be expressed as

$$
\Delta P=U_{d c r e f}\left(I_{d c}-I_{d c r e f}\right)=\frac{\Delta U_{d c} U_{d c r e f}}{K}
$$

As can be observed in (4) and (8), the traditional droop coefficient $K$ affects control of DC voltage and allocation of unbalanced power.

The traditional droop coefficient $K$ is fixed at a constant level. Without considering the power margin of the converter station, it is easy to cause overload of the converter station and massive DC voltage deviation.

To solve the problems of the traditional DC voltage droop control strategy, this paper introduces the droop coefficient influence factor, which is defined as

$$
\alpha= \begin{cases}\frac{U_{d c r e f} I_{d c}}{P_{\max }} & I_{d c}>I_{d c r e f} \\ \frac{\left(P_{\max }-U_{d c r e f} I_{d c}\right)}{P_{\max }} & I_{d c}<I_{d c r e f}\end{cases}
$$

where $P_{\max }$ is the rated active capacity of the converter station.

Without loss of generality, there is

$$
0<U_{d c r e f} I_{d c}<U_{d c \max } I_{d c \max }=P_{\max }
$$

Equations (9) and (10) shows $0<\alpha<1$

In terms of the DC voltage adaptive droop control strategy, the adaptive droop coefficient is defined as

$$
K^{*}=K^{\alpha}-1 \quad(K>1)
$$

In terms of the hybrid-MTDC system, $P$ is the actual power of the converter station. When the actual DC current of the converter station $I_{d c}$ is larger than the DC current reference value $I_{d c r e f}$, the smaller $I_{d c}$ is, the larger the power margin $P_{\max }$ $P$ of the converter station is. When the actual DC current of the converter station $I_{d c}$ is less than the DC current reference value $I_{d c r e f}$, the larger $I_{d c}$ is, the larger the power margin $P$ of the converter station is. According to (9) and (11), the converter station with larger power margin has a smaller adaptive droop coefficient $K^{*}$. As a result, the unbalanced power allocated to the converter station is relatively more. Contrarily, the converter station with smaller power margin has a larger adaptive droop coefficient $K^{*}$, consequently, the unbalanced power allocated to the converter station is relatively less.

Substituting (11) into (4), the DC voltage deviation of the DC voltage adaptive droop control strategy is

$$
\Delta U_{d c 1}=U_{d c}-U_{d c r e f}=\left(K^{\alpha}-1\right)\left(I_{d c}-I_{d c r e f}\right)
$$

Compared with the DC voltage deviation of traditional droop control, Equation (13) can be formulated as follow 


$$
\Delta U_{d c 1}-\Delta U_{d c}=\left(K^{\alpha}-1-K\right)\left(I_{d c}-I_{d c r e f}\right)
$$

Based on $K^{\alpha}-1-K<0$, Equation (14) can be obtained as follow

$$
\left|\Delta U_{d c 1}\right|<\left|\Delta U_{d c}\right|
$$

According to (14), compared with the traditional DC voltage droop control, the DC voltage adaptive droop control minimizes DC voltage deviation.

\section{Simulation and Discussion}

In order to verify the feasibility and effectiveness of the proposed control strategy, the four-terminal hybrid HVDC system shown in Fig. 1 is built in PSCAD/EMTDC. VSC1 and VSC2 adopt the constant active power control; LCC3 and LCC4 apply DC voltage droop control. Parameters of the system simulation are shown in TABLE I. From Fig. 5 to Fig. 7 , ADC represents adaptive droop control, and TDC represents traditional droop control.

TABLE I

PARAMETERS OF THE SIMULATION SYSTEM

\begin{tabular}{cc}
\hline Parameter & Value \\
\hline DC voltage reference value $U_{d c r e f} / \mathrm{kV}$ & 400 \\
Rated active capacity of VSC1 $/ \mathrm{MW}$ & 500 \\
Rated active capacity of VSC2 $/ \mathrm{MW}$ & 500 \\
Rated active capacity of LCC1/MW & 500 \\
Rated active capacity of LCC $2 / \mathrm{MW}$ & 500 \\
DC current upper limit of LCC $/ \mathrm{kA}$ & 1.19 \\
LCC converter transformer ratio/(kV/kV) & $300 / 200$ \\
The traditional droop coefficient $K$ & 16.8 \\
\hline
\end{tabular}

\section{A. Increase of Active Power}

In the initial state, the active power instruction values of VSC1 and VSC2 are $250 \mathrm{MW}$ and $400 \mathrm{MW}$ respectively; the DC current reference values of LCC3 and LCC4 are $0.52 \mathrm{kA}$ and $1.0 \mathrm{kA}$ respectively. At $6 \mathrm{~s}$, the active power instruction value of VSC1 rushes to $425 \mathrm{MW}$. The simulation results are shown in Fig. 5.
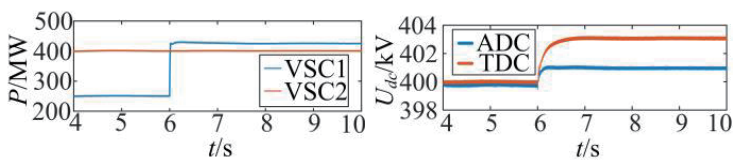

(a) Active power of VSCs

(b) DC voltage
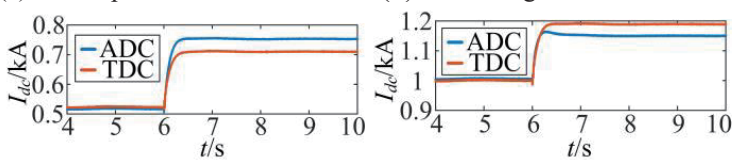

(c) DC current of LCC3

(d) DC current of LCC4
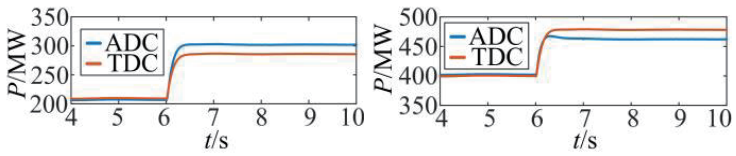

(e) Active power of LCC3

(f) Active power of LCC4

Fig. 5 Simulation waveforms of increase of active power

The simulation results show that the DC voltage increases when the active power of VSC1 increases at $6 \mathrm{~s}$. For the traditional DC voltage droop control strategy, the DC voltage in- creases from $400 \mathrm{kV}$ to $403 \mathrm{kV}$. At the same time, the DC current of two LCC converter stations both increase $0.19 \mathrm{kA}$. As a result, the DC current of LCC4 reaches its upper limit value $1.19 \mathrm{kA}$, which causes LCC4 to switch to the constant current control mode. In addition, the unbalanced power shared by LCC3 and LCC4 are 78 MW equally. However, by utilizing the DC voltage adaptive droop control strategy, the DC voltage increases from $400 \mathrm{kV}$ to $401 \mathrm{kV}$. At the same time, the DC current of LCC 3 increases by $0.234 \mathrm{kA}$, whereas the DC current of LCC4 increases by $0.15 \mathrm{kA}$. Owing a larger power margin, the unbalanced power shared by LCC3 is 94 MW. Meanwhile, the unbalanced power shared by LCC4 with smaller power margin is $61 \mathrm{MW}$.

According to the above analysis, for the DC voltage adaptive droop control strategy, the LCC converter stations share unbalanced power based on power margins. Hence, it avoids the situation that LCC4 converter station switches to constant current control mode due to overload. At the same time, the DC voltage deviation decreases. In addition, it can be observed that the hybrid-MTDC system with DC voltage adaptive droop control has faster response speed.

\section{B. Decrease of Active Power}

In the initial state, the active power instruction values of VSC1 and VSC2 are $250 \mathrm{MW}$ and $400 \mathrm{MW}$, respectively, and the DC current reference values of LCC3 and LCC4 are 0.52 $\mathrm{kA}$ and $1.0 \mathrm{kA}$ respectively. At $6 \mathrm{~s}$, the active power instruction value of VSC2 converter station rushes to $160 \mathrm{MW}$. The simulation results are shown in Fig. 6.

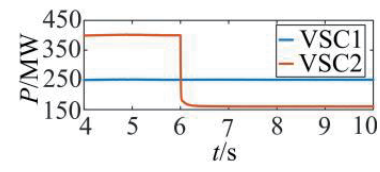

(a) Active power of VSCs

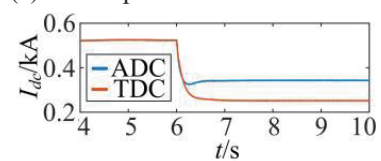

(c) DC current of LCC3

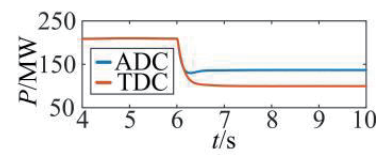

(e) Active power of LCC3

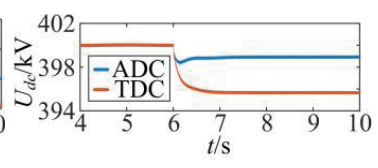

(b) DC voltage
Fig. 6 Simulation waveforms of decrease of active power

As shown in Fig.6, the DC voltage decreases when active power of VSC2 decreases. For the traditional DC voltage droop control strategy, the DC voltage decreases from $400 \mathrm{kV}$ to $395.5 \mathrm{kV}$. At the same time, the DC current of two LCC converter stations decreases by $0.27 \mathrm{kA}$, and the unbalanced power shared by LCC 3 and LCC4 are $110 \mathrm{MW}$ equally. For the DC voltage adaptive droop control strategy, the DC voltage decreases from $400 \mathrm{kV}$ to $399 \mathrm{kV}$. At the same time, the DC current of LCC3 decreases by $0.177 \mathrm{kA}$, while the DC current of LCC4 decreases by $0.37 \mathrm{kA}$. Owing a larger power margin, the unbalanced power shared by LCC4 is 149 MW. Meanwhile, the unbalanced power shared by LCC3 with smaller power margin is $71 \mathrm{MW}$. 
From the above analysis, it can be observed that the converter stations employing the DC voltage adaptive droop control strategy share the power based on power margins, which ensures more unbalanced power shared by the converter station with larger power margin. At the same time, the DC voltage deviation decreases. In addition, it is shown that the hybrid-MTDC system with the DC voltage adaptive droop control has faster response speed.

\section{LCC3 Being Out of Operation}

In the initial state, the active power instruction values of VSC1 and VSC2 are $300 \mathrm{MW}$ and $200 \mathrm{MW}$ respectively, and the DC current reference values of LCC3 and LCC4 are 0.5 kA and $0.69 \mathrm{kA}$ respectively. At $6 \mathrm{~s}, \mathrm{LCC} 3$ exits due to a failure. The simulation results are shown in Fig.7.
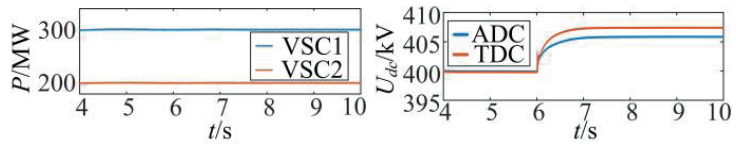

(a) Active power of VSCs

(b) DC voltage
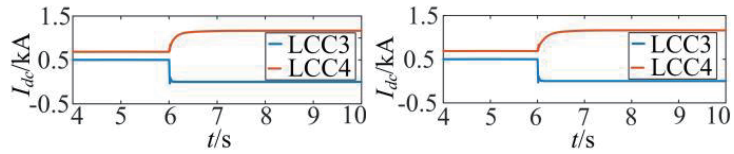

(c) DC current of LCC with adaptive droop control

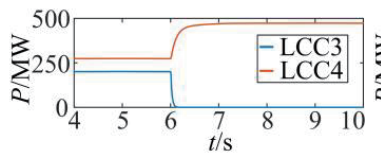

(d) DC current of LCC with traditional droop control

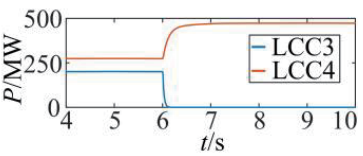

(e) Active power of LCC with adaptive droop control

(f) Active power of LCC with traditional droop control

Fig. 7 Simulation waveforms of LCC3 being out of operation

The simulation results in Fig. 7 show that when LCC3 exits at $6 \mathrm{~s}$, LCC4 regulates active power. For the traditional DC voltage droop control strategy, the DC voltage increases from $400 \mathrm{kV}$ to $407.5 \mathrm{kV}$. However, by using the DC voltage adaptive droop control strategy, the DC voltage increases from 400 $\mathrm{kV}$ to $406 \mathrm{kV}$. No matter which control strategy is utilized, the DC current and active power changes of LCC3 and LCC4 are basically the same. Compared with traditional droop control, DC voltage adaptive droop control minimizes DC voltage deviation while maintaining the stability of the system.

\section{Conclusion}

In this paper, a DC voltage adaptive droop control strategy has been proposed for the power allocation and the DC voltage control in the hybrid-MTDC system. The main conclusions are as follows:

(1) The DC voltage adaptive droop control strategy takes into account power margin of the converter station according to the actual operating conditions, so that the converter station with the proposed strategy in the hybrid-MTDC can share power according to its own power regulating ability. As a result, the converter station avoids the overload caused by insufficient margin.

(2) When power flow changes in the hybrid-MTDC system occur, the DC voltage of the new steady state is closer to the
DC voltage of the original steady state, that is to say, the DC voltage deviation decreases.

(3) There is no need for high-speed communications between converter stations, hence the system responds quickly.

\section{References}

[1] Guangfu Tang, et al., "Multi-terminal HVDC and DC-grid technology," Proceedings of the CSEE, 33, pp. 8-17, April 2013.

[2] Dianguo Xu, et al., "Review on control strategies of multiterminal direct current transmission system," Transactions of China Electrotechnical Society, 30, pp. 1-12, September 2015.

[3] Yongping Wang, et al., "Hybrid high-voltage direct current transmission technology and its development analysis," Automation of Electric Power Systems, 41, pp. 156-167, April 2017.

[4] Weihuang Huang, et al., "A novel refurbishment scheme for reforming the existing LCC-HVDC to hybrid HVDC," Proceedings of the CSEE, 37, pp. 2861-2868, May 2017.

[5] Abdel-Khalik A S, et al., "Optimum power transmission-based droop control design for multi-terminal HVDC of offshore wind farms," IEEE Transactions on Power Systems, 28, pp. 34013409, August 2013.

[6] Prieto-Araujo E, et al., "Methodology for droop control dynamic analysis of multiterminal VSC-HVDC grids for offshore wind farms," IEEE Transactions on Power Delivery, 26, pp. 24762485, May 2011.

[7] Aragüés-Peñalba M, et al., "Optimum voltage control for loss minimization in HVDC multi-terminal transmission systems for large offshore wind farms,"Electric Power Systems Research, 89, pp. 54-63, August 2012.

[8] Rouzbehi K, et al., "DC voltage control and power sharing in multiterminal DC grids based on optimal DC power flow and voltage-droop strategy," IEEE Journal of Emerging \& Selected Topics in Power Electronics, 2, pp. 1171-1180, July 2014.

[9] Fayou Yan, Guangfu Tang, et al., "An improved droop control strategy for MMC-based VSC-MTDC systems," Proceedings of the CSEE, 34, pp. 397-404, January 2014.

[10] Chaudhuri N R, "Adaptive droop control for effective power sharing in multi-terminal DC (MTDC) grids," IEEE Transactions on Power Systems, 28, pp. 21-29, February 2013.

[11] Haifeng Li, et al., "DC voltage droop-control strategy for VSCbased HVDC grid," Automation of Electric Power Systems, 40, pp. 40-46, November 2016. 